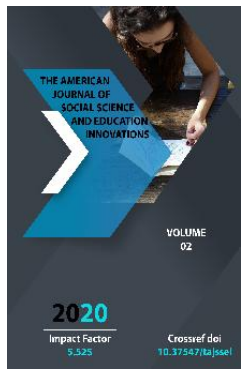

\title{
Some Issues Related To The Study Of Drama Language: The Use Of Dialog
}

\author{
Ikramova Gulhida Ahmadillo kizi \\ Lecturer of the Department of Primary Education, Fergana State University, Uzbekistan
}

Journal Website:

http://usajournalshub.c

om/index,php/tajssei

Copyright: Original

content from this work

may be used under the

terms of the creative

commons attributes

4.0 licence.

\section{ABSTRACT}

The article describes some features of dialogue introduction as a speech structure in different literary genres. Dialogues in drama and prose are correlated with the dialogue model of colloquial speech.

\section{KEYWORDS}

Language of drama, dialogue, lyrics, drama, elements of a dialogue, dialogue model.

\section{INTRODUCTION}

Dialogue as a form of speech is represented in different literary genders and each of them has its own characteristics, which are associated with the specifics of the organization of the literary text. In the lyric text, dialogue as a speech structure, which is an exchange of replicas of subjects of communication, is rarely reproduced in comparison with other literary genders drama and prose, since the lyrics are monologue in nature. The dialogues available in the lyric text are usually distinguished by minimal syntactic complexity, short length of replicas, simplicity of structure (most often this is a replica pair).

\section{MATERIALS AND METHODS}

The researchers note the existence in the lyrics of separate forms inherent in oral dialogue I.I. Kovtunova refers to the language of drama as an address, a second person, an imperative mood, a question, and draws attention to the fact that their functions in poetic texts are becoming more complicated and transformed, that each of these forms in poetry has not only those usual for oral speech, but also its specific features. Based on 
the peculiarities of oral communication, I.I. Kovtunova singles out strong and weak signs of dialogue. Strong signs suggest a certain reaction from the interlocutor. These include command and question. Weak signs do not require a response from the interlocutor, they are designed for attention and understanding, but not directly for a response. This is the second person and the appeal.

The change in the status of grammatical categories, the complication of their functions in comparison with their primary function in oral speech occurs under the influence of the peculiar conditions of speech communication in poetry. This is a complex structure of reference and poetic message, the complication of the position of the speech subject and addressee, the special nature of the language (poetic language) and, finally, the genre of written speech, in which the means of oral communication acquire a different functional status.

Appeal, second person, imperative mood, question suggest the interlocutor to whom they are directly directed. The originality of these categories in the lyrics is associated with the absence of interlocutors at the time of speech, with the possible unusual character of the interlocutors in lyric poetry, as well as with extraordinary complication of relations between the subject of speech and its addressee [3].

N.N. Ivanova speaks of the dialogic nature of lyrics in a broad sense, which means "the nature of the relations expressed in it between the author (lyric hero) and the modern mass reader-listener, that essential quality of the poetic word that affects the very essence of lyric poetry, as if turning it from author's lyric monologue in a dialogue- the form of a conversation between the author and the reader "[1, p. 211].

S.N. Broitman believes that the process of dialogization of lyrics is the introduction into its subject-shaped fabric of "I" as "another" [2, p. 533]. Adhering to the view of the lyrics as a specific form of the relationship of subjects, he comes to the conclusion that the isolated "l" in the lyrics, which "by their very nature, more directly grows out of the subject than the epic and drama" [2, p. 531], is fundamentally impossible: "|" always exists only in relation to other subjective spheres. Therefore, "in order to get to the" person in person "in the lyrics, it is necessary to consider how in it the relationship" I - the other "is realized in the inner sphere of selfawareness of the personality and in its real connections with the" other "'" [2, p. 528].

The specificity of the dialogue in the drama is explained by the peculiarities of the dramatic text, consisting almost exclusively of the characters' speech, organized as a dialogue, monologue, monologue remark and polylogue.

Dialogue in the drama is studied in the following directions: the methods of individual speech characteristics of the characters, the schemes of coupling of dialogical remarks, the communicative articulation of the dialogue, the structural features of the components, the typology of structural components and dialogue are studied. When studying the structure, special attention is paid to the replica-reaction as a unit, which, due to its functional orientation, has specific features in comparison with the replica-stimulus (incomplete or incomplete sentences, replicapickups, replica-repetitions, inverted word 
order, distribution of parts of a complex sentence in the dialogue and etc.). [4].

Types of dialogue in drama are distinguished based on the number of participants or semantic criteria. N.K. Piksanov proposed to single out tercets, quartets, quintets and gave them a general definition - ensembles [10]. M.B. Borisova, depending on the number of participants and the role played, distinguishes the actual dialogue, parallel dialogue, polylogue [9]. On the basis of semantic criteria, a dialogue-dispute, a dialogueconfidential explanation, a dialogue-emotional conflict (quarrel), a dialogue-unison is distinguished.

Dialogue in the drama correlates with lively colloquial speech; typical features characterizing dialogue as a structure reflecting natural speech are revealed. The "signals" of colloquiality are mainly various syntactic phenomena inherent in colloquial speech (specific properties of oral speech at other levels - morphological, background technical - almost never used as less expressive).

\section{RESULTS AND DISCUSSIONS}

Dramatic text is not only meant to be read but also to be played on stage. Dialogue in drama is therefore highly informative. He moves the action, develops the plot, since the author's text is reduced to a minimum.

In prose works, the writer has the opportunity to create a full-fledged dialogical situation, since here the author represents both the verbal behavior of the character and describes the non-verbal reality accompanying this behavior. The author needs to give speech characteristics to the characters, to take care of the impression of the naturalness of their speech. The dialogue is thought out, processed by the author, addressed to the reader, it is "an organic part of a work of art, subordinate to the general tasks of the work" [6].

Yu.M. Lotman, comparing prose with poetry, notes that "prose in the modern sense of the word appears in Russian literature from Pushkin. It combines at the same time ideas about high art and about non-poetry. Behind this stands the aesthetics of "real life" with its conviction that the source of poetry is reality. Thus, the aesthetic perception of prose became possible only against the background of poetic culture. Prose is a phenomenon later than poetry, which arose in the era of a chronologically more mature aesthetic consciousness. Precisely because prose is aesthetically secondary in relation to poetry and is perceived against its background, the writer can safely bring the style of prose artistic narration closer to colloquial speech, without fear that the reader will lose the feeling that he is dealing not with reality, but with its recreation. Thus, despite its apparent simplicity and closeness to ordinary speech, prose is aesthetically more complex than poetry, and its simplicity is secondary " [7].

E.V. Paducheva also believes that "the narrative text is written in the same language in which daily communication takes place," but the language functions in the narrative text and in ordinary conversations differently [8]. This idea can also be attributed to the "creation" of dialogical communication in the space of a literary prose text.

When creating a model of dialogue between characters in prose, the author, on the one hand, relies on a similar model of natural speech communication and constructs a 
dialogue of characters in which the parameters of natural dialogue are reproduced. On the other hand, the dialogue of characters, designed for the reader's cocreation, for his perceiving consciousness, is subjected by the author of the work in the graphic space of the text to transformations associated with changes in the parameters of natural dialogical communication. As the creator of the dialogue of characters, he can change different parameters: ontological (characters who do not speak the language can be included in dialogical communication), replication (in the dialogue, replicas of only one person can be graphically represented.

Dialogue communication is represented in prose by a fragment of the text. Due to the fact that the text is devoid of spontaneity, chaos, it is always framed and organized in a certain way.

Natural conversational dialogue, which is the main form of real speech existence and has its own specific features, is reproduced in a prose work as a piece of text representing the dialogue of the characters of a work of art. A dialogical fragment of the text conveys a dialogical situation adequate to a real one, corresponding to the parameters of a natural spoken dialogue, which is necessary for the reader to perceive the dialogical communication of characters as corresponding to objective reality.

A dialogic fragment of a text (one can call it a microtext in the structure of a prose work - a macrotext) is a certain structured combination of the character and author's speech plans, which together represent the dialogical communication of the characters of a work of art. In a prose work, it is a part of the macro text, ordered, organized, structured.

The components of a dialogical piece of text include:

- $\quad$ speech plan of characters (replicas of two characters);

- the author's speech plan, including an introduction, containing, as a rule, the designation of the participants in the dialogue, the time and place of its holding; remarks that include a verb denoting a speaking process, and a name or pronoun denoting a character who utters a stimulus or response; author's deviations, comments, parts of a narrative and descriptive nature, related in content to a dialogical fragment of the text.

The author of a prose fiction has the ability to create a full-fledged dialogical situation, since he imagines both the verbal behavior of the characters in the work and the non-verbal reality that accompanies it. The replicas (at least two: a stimulus replica and a response replica) belonging to the characters are mandatory components of the character speech plan of a dialogic text fragment, reflecting the model of real communication. Representation in the graphic space of a work of verbal and non-verbal reality is usually assigned to speech plans of a prosaic work of art: verbal behavior represents the speech plane of the characters, non-verbal behavior the speech plane of the author.

\section{CONCLUSION}

The dialogue of a work of art is created by one person - the author of the work, in connection with which we can speak of varying degrees of his participation in the formation of a 
dialogical fragment of the text. The replica as the main component of the dialogical fragment, expressed by the speech plan of the characters created by the author, forms dialogical communication in the reader's mental activity, projected onto the natural model of speech activity. The degree of conventionality of the representation of speech communication in such a model is minimal. In the case of expressing one or both remarks by the author's speech plan, the degree of convention increases.

\section{REFERENCES}

1. Ivanova N.N. Dialogue in modern lyrics // Problems of Structural Linguistics, 1982. Moscow, 1984.

2. Broitman S.N. The Subject Structure of Russian Lyrics of the 19th Century in historical coverage // Izv. Academy of Sciences of the USSR. Literature series and language. 1988. T. 47, No. 6. S. 527 538.

3. Muhamadjonovna, S. D. (2020). The development of sociolinguistic competence of future English language teachers through computer technologies. European Journal of Research and Reflection in Educational Sciences, 8 (3) Part II, 147-150.

4. Polishchuk G.G., Sirotinina O.B. Conversational speech and artistic dialogue // Linguistics and poetics. M., 1979.

5. Khalizev V.E. Monologue and Dialogue in Drama // Izv. Academy of Sciences of the USSR. Literature series and language. 1981. T. 40, No. 6.

6. Lagutin V.I. Problems of the analysis of artistic dialogue (to the pragmalinguistic theory of drama). Chisinau, 1991.
7. Borisova M.B. The language of drama // Problems of stylistic analysis. SPb., 1995.

8. Polishchuk G.G. Speech behavior in the structure of a literary text // Problems of speech communication. Saratov, 2000.

9. Abduvaliyeva, N. A. (2020). SOME FORMS OF REFERENCE (ADDRESSING) IN UZBEK DRAMAS. Theoretical \& Applied Science, (1), 23-26.

10. Ikromova. Gulhida. A. (2020). Developing the speech of primary school pupils through the folklore. ACADEMICIA: An International Multidisciplinary Research Journal, 10(5), 567-571.

11. Ярашова, Н. Ж. (2019). ПРОЯВЛЕНИЕ ИНТОНАЦИИ У ДЕТЕЙ ПОСРЕДСТВОМ ОБРАЩЕНИЯ. In ТРадициИ И новациИ В профессиональной подготовке и деятельности педагога (рр. 128-130).

12. Jumaevna, Y. N. (2020). Occupation of the child's personal mental status in dialogual speech. Asian Journal of Multidimensional Research (AJMR), 9(5), 405-408.

13. Jumayevna, Y. N. (2019). Linguo culture logical features of metaphors in children's literature (On the example of khudayberdi tokhtabayev's creative work). ACADEMICIA: An International Multidisciplinary Research Journal, 9(4), 139-145. 